\title{
Multimodal luminescence spectra of ion-implanted silica
}

\author{
(C) H.-J. Fitting", Roushdey Salh, B. Schmidt* \\ Institute of Physics, University of Rostock, \\ D-18051 Rostock, Germany \\ * Research Center Rossendorf, Institute of Ion Beam Physics and Materials Research, P.O. Box 510119, \\ D-01314 Dresden, Germany
}

(Получена 12 сентября 2006 г. Принята к печати 3 октября 2006 г.)

\begin{abstract}
Main luminescence bands in silica $\mathrm{SiO}_{2}$ are the red luminescence $\mathrm{R}(650 \mathrm{~nm}, 1.9 \mathrm{eV})$ of the non-bridging oxygen hole center, the blue band B $(460 \mathrm{~nm}, 2.7 \mathrm{eV})$ and the altraviolet luminescence UV $(290 \mathrm{~nm}, 4.3 \mathrm{eV})$ both related commonly to oxygen deficient centers. In the present work we will enhance or replace either the first or second constituent of $\mathrm{SiO}_{2}$, i.e. silicon or oxygen, isoelectronically by additional implantation of respective ions. Thus thermally oxidized $\mathrm{SiO}_{2}$ layers have been implanted by different ions of the IV group $(\mathrm{C}, \mathrm{Si}, \mathrm{Ge}, \mathrm{Sn}, \mathrm{Pb})$ and of the VI group $(\mathrm{O}, \mathrm{S}, \mathrm{Se})$ with doses up to $5 \cdot 10^{16} \mathrm{~cm}^{-2}$ leading to an atomic dopant fraction of about 4 at $\%$ at the half depth of the $\mathrm{SiO}_{2}$ layers. Very surprisingly, the cathodoluminescence spectra of oxygen and sulfur implanted $\mathrm{SiO}_{2}$ layers show besides characteristic bands a sharp and intensive multimodal structure beginning it the green region at $500 \mathrm{~nm}$ up to the near infrared. The energy step differences of the sublevels amount in average $120 \mathrm{meV}$ and indicate vibration associated electronic states, probably of $\mathrm{O}_{2}^{-}$interstitial molecules.
\end{abstract}

PACS: $78.60 . \mathrm{Hk}, 61.72 . \mathrm{Ww}$

\section{Introduction}

Silicon dioxide is an important material for microelectronic devices, optical fiber communications, and even photonics [1]. The performance of electronic and optical devices depends, in part, on the presence of extrinsic as well as intrinsic defects in the $\mathrm{SiO}_{2}$ network [2]. Cathodoluminescence (CL) microscopy and spectroscopy in a scanning electron microscope (SEM) is a technique with sensitivity to and high spatial resolution of luminescent defect centers in insulator materials $[3,4]$, especially in thin layers.

The main luminescent bands at room temperature (RT) are the red luminescence $\mathrm{R}(650 \mathrm{~nm}, 1.9 \mathrm{eV})$ of nonbridging oxygen hole center (NBOHC), the blue band $\mathrm{B}$ $(460 \mathrm{~nm}, 2.7 \mathrm{eV})$ and the ultraviolet luminescence UV $(290 \mathrm{~nm}, 4.3 \mathrm{eV})$ both attributed to the oxygen deficient center $(\mathrm{ODC})[5,6]$. At low temperatures a green-yellow luminescence band $\mathrm{G}(540 \mathrm{~nm}, 2.3 \mathrm{eV})$ is observed in the first few seconds of irradiation and had been attributed to the self-trapped exciton (STE) [7]. Moreover, a yellow band $\mathrm{Y}(560 \mathrm{~nm}, 2.2 \mathrm{eV})$ appears after long time of irradiation, i. e. after doses of $2 \mathrm{~A} \cdot \mathrm{s} / \mathrm{cm}^{2}[8]$.

In order to investigate whether the different luminescent centers are related to oxygen or to silicon, we have compared non-stoichiometric $\mathrm{SiO}_{2}$ layers produced by direct ion implantation. Oxygen implantation as well as, on the other hand, direct silicon implantation led to an oxygen surplus as well as an oxygen deficit, respectively [4]. As the main experimental result we could state:

- oxygen increases the red band $\mathrm{R}$ in $\mathrm{SiO}_{2}$ but does not affect the blue band $\mathrm{B}$;

— silicon increases the blue (B) luminescence, but reduces the red $(\mathrm{R})$ band.

\footnotetext{
I E-mail: hans-joachim.fitting@uni-rostock.de Fax: +49-381-4986802
}

Based on these findings we proposed a new model of defect creation by stressing the role of mobile oxygen in defect transformation [4]. Similar results were obtained after $\mathrm{Si}^{+}$ and $\mathrm{O}^{+}$implantation by photoabsprption measurements [9].

In the present work we will either enhance or replace the second constituent oxygen isoelecronically by additional oxygen or sulfur implantation, respectively. Analogously to oxygen surplus in the former work [4], we expect a strong influence on the red luminescence band $\mathrm{R}$ of the NBOHC. The results obtained with multimodal spectra are very surprising, having encouraged us to two first rapid communications $[10,11]$ to look for further discussion.

\section{Experimental}

CL spectra and dose measurements (Rostock) were performed in a digital scanning electron microscope (Zeiss DSM 960) via a parabolic mirror collector, a spectrograph (Spex-270M) and a CCD camera (Princenton Instr., EEV $1024 \times 256)$ [4]. CL spectra ranging from 200 to $800 \mathrm{~nm}$ (i.e. 1.5 to $6.5 \mathrm{eV}$ ) were accumulated in single shot mode within a time of $1 \mathrm{~s}$ and with a spectral resolution of $4 \mathrm{~nm}$. A temperature controlled stage provides sample temperatures between 80 and $670 \mathrm{~K}$. In general, the CL excitation was performed with an electron energy of $5-10 \mathrm{keV}$ and a beam current of $I_{0}=500 \mathrm{nA}$. This beam is scanned over an area of $106 \times 110 \mu \mathrm{m}$ providing a current density of $j_{0} \approx 5 \cdot 10^{-3} \mathrm{~A} / \mathrm{cm}^{2}$.

As a special samples for oxygen ion $\left(\mathrm{O}^{+}\right)$implantation we have used amorphous „dry“ $\mathrm{SiO}_{2}$ layers, $100 \mathrm{~nm}$, thermally grown on Si substrate by dry oxidation at $1000^{\circ} \mathrm{C}$. The oxygen implantation was performed here with an energy $E_{\mathrm{O}^{+}}=20 \mathrm{keV}$ and a dose $3 \cdot 10^{16} \mathrm{~cm}^{-2}$. For all other kinds of implantation $500 \mathrm{~nm}$ thick $\mathrm{SiO}_{2}$ layers, wet oxidized at $1100^{\circ} \mathrm{C}$, were used. Implantations of $\mathrm{C}^{+}, \mathrm{Si}^{+}, \mathrm{Ge}^{+}$, 


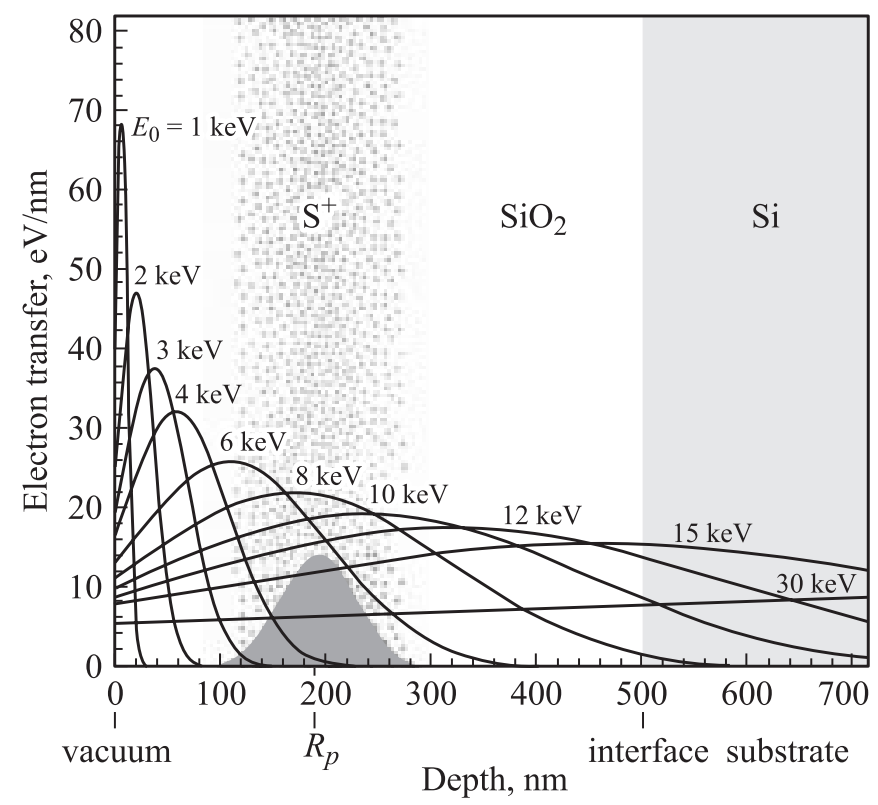

Figure 1. Electron beam excitation densities in $\mathrm{SiO}_{2}$ layers for different beam energies $E_{0}$ allowing a CL depth profiling. Here a sulfur profile $\mathrm{S}^{+}$is implanted with an ion energy $\mathrm{E}_{\mathrm{S}^{+}}=150 \mathrm{keV}$, the mean projected range $R_{p}=190 \mathrm{~nm}$.

$\mathrm{Sn}^{+}, \mathrm{Pb}^{+}$, as well as $\mathrm{O}^{+}, \mathrm{S}^{+}, \mathrm{Se}^{+}$into these layers were performed with energies $E^{+}=65,150,350,400,400$, and $100,150,300 \mathrm{keV}$, respectively, and a unique dose $5 \cdot 10^{16} \mathrm{~cm}^{-2}$. These implantation energies and doses led to an atomic dopand fraction of about 4 at $\%$ at nearly the half depth of the oxide layers (see Fig. 1 and [4]). Afterwards a post-implantation thermal annealing has been performed for $30 \mathrm{~min}$ in dry nitrogen at the temperature $T_{a}=900-1000^{\circ} \mathrm{C}$.

\section{Results and discussion}

First of all in Fig. 2 (left above), we see the typical CL spectra of dry and wet oxidized $\mathrm{SiO}_{2}$ measured at room temperature. Besides the main bands, red $\mathrm{R}(660 \mathrm{~nm}$, $1.9 \mathrm{eV})$, blue B $(460 \mathrm{~nm}, 2.7 \mathrm{eV})$, and UV $(290 \mathrm{~nm}, 4.4 \mathrm{eV})$, we recognize the yellow band $\mathrm{Y}(570 \mathrm{~nm}, 2.2 \mathrm{eV})$ appearing and increasing at RT after a longer time of irradiation in wet oxide. On the other hand, in dry oxide the red band $\mathrm{R}$ is increasing in intensity from almost zero to saturation whereas in wet oxide the red band $\mathrm{R}$ is already present after the beginning of irradiation.

Then in Fig. 2 (left middle), the spectra of $\mathrm{SiO}_{2}$ with additional implanted oxygen are shown. In order to avoid water formation and binding of oxygen, we have chosen „dry“ oxidized $\mathrm{SiO}_{2}$ layers as described above. Because of slower oxidation they are of less thickness, $d=100 \mathrm{~nm}$. Thus the overall CL intensity is about one order of magnitude lower than in $500 \mathrm{~nm}$ thick oxides. But the surprisingly new feature of the spectra appears in its multiple regular structure from the green $(G)$ over the yellow $(\mathrm{Y})$ and red $(\mathrm{R})$ regions into near infrared (IR).

An identical multimodal structure, but still more sharp and regular, is found in sulfur implanted layers, as shown in Fig. 2 (left below), there the cathodoluminescence spectra of $\mathrm{S}^{+}$doped silicon dioxide are presented for liquid nitrogen (LNT) and room (RT) temperature as well as with their time dependence. Obviously, the high violet (V) intensity at $410 \mathrm{~nm}$ is assigned to sulfur $\mathrm{S}^{+}$implantation. Moreover, the sharp and intensive multi-step emission spectra in the green-yellow-red-near IR region $(500-820 \mathrm{~nm})$ is observed for these layers as in $\mathrm{O}^{+}$implanted layers. The exact band positions in wavelengths are given in Fig. 2 (left, respective parts). They correspond to almost equidistance energy steps of $140 \mathrm{meV}$ in the green $(\mathrm{G})$ region then slightly decreasing to $110 \mathrm{meV}$ in the IR region, shown already in [10]. Thus the mean energy step width is about $120 \mathrm{meV}$.

After longer irradiation of about $1 \mathrm{~min}$, i.e. an electron beam dose of $0.3 \mathrm{~A} \cdot \mathrm{s} / \mathrm{cm}^{2}$, the multiple structure in oxygen doped $\mathrm{SiO}_{2}: \mathrm{O}$ and sulfur doped silica $\mathrm{SiO}_{2}: \mathrm{S}$ disappears (probably destroyed by the electron beam) and the characteristic red band $\mathrm{R}(660 \mathrm{~nm})$ of the NBOHC in $\mathrm{SiO}_{2}$ becomes visible besides remaining components at the blue band B $(460 \mathrm{~nm})$ position and in the yellow region at 560 and $590 \mathrm{~nm}$. On the other hand, the sulfur associated violet band $\mathrm{V}(410 \mathrm{~nm})$ remains still visible.

However, in $\mathrm{Se}^{+}$implanted layers (Fig. 2, left bottom), also isoelectrically implanted with regard to oxygen, the multimodal structure does not appear. Therefore a series of other bands becomes visible, partially $\mathrm{SiO}_{2}$ matrix related and, on the other hand, specially dopant-related bands appear. Similar spectra are observed for isoelectron dopants with respect to silicon (Fig. 2, right). As already mentioned, Si surplus increases the blue ODC luminescence at $460 \mathrm{~nm}$ whereas Ge and Sn implantation lead to a huge violet band at 410 and $440 \mathrm{~nm}$, respectively. But, here we want to focus our attention to the multimodal spectra of oxygen and sulfur implanted layers.

Hence the mean step width in the multimodal spectra of $\mathrm{SiO}_{2}: \mathrm{O}$ and $\mathrm{SiO}_{2}: \mathrm{S}$ amounts about $120 \mathrm{meV}$, this energy difference may correspond to a series of almost equidistant vibronic levels of non-saturated sulfur radicals $\equiv \mathrm{Si}-\mathrm{S} \bullet$ or $\equiv \mathrm{Si}-\mathrm{O}-\mathrm{S} \bullet$ formed during implantation and thermal annealing analogously to the red $\mathrm{R}$ band center of the non-bridging oxygen $(\mathrm{NBOHC}) \equiv \mathrm{Si}-\mathrm{O} \bullet$ in pure $\mathrm{SiO}_{2}$. Even the vibronic step widths are decreasing with lower photon energy, beginning from $\Delta E=140 \mathrm{meV}$ at $h v=2.48 \mathrm{eV}$ and dropping to $\Delta E=110 \mathrm{meV}$ at $h v=1.51 \mathrm{eV}$, indicating a widened (sub-quadratic) potential curve of the luminescence ground states with compressed higher vibronic levels in terms of a adiabatic configuration coordinate model. But we find exactly the same multimodal structure in oxygen implanted dry $\mathrm{SiO}_{2}$ as before in sulfur implanted $\mathrm{SiO}_{2}$ layers. It leads us to the conclusion that not sulfur but oxygen seems to be the source of these multiple spectra. We know already that oxygen is 
Energy, eV
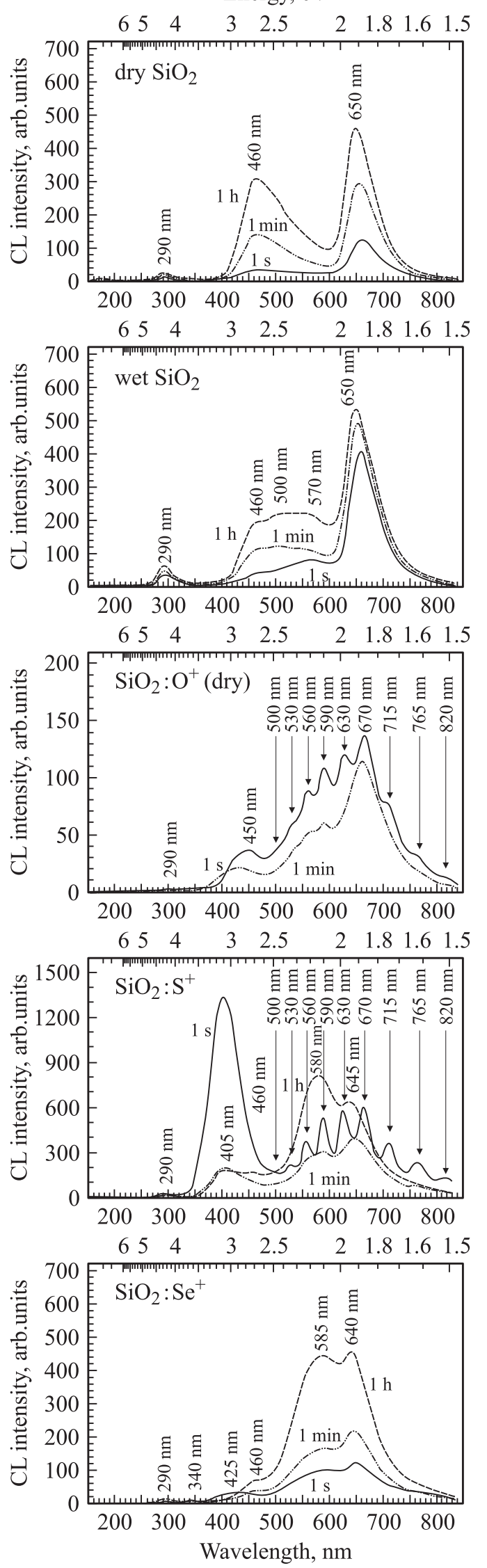

Energy, eV
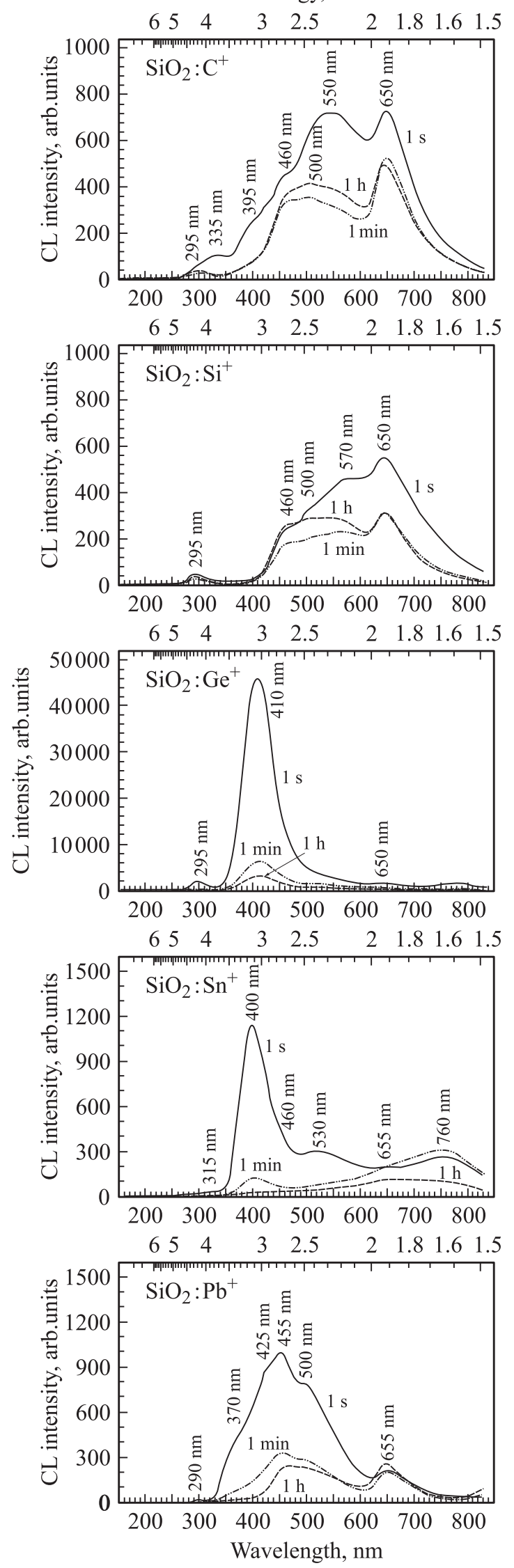

Figure 2. $\mathrm{CL}$ spectra of dry and wet $\mathrm{SiO}_{2}$ layers pure as well as implanted with different ions: isoelectrically to $\mathrm{O}$ (left) and to $\mathrm{Si}$ (right). The $\mathrm{SiO}_{2}: \mathrm{O}^{+}$and $\mathrm{SiO}_{2}: \mathrm{S}^{+}$samples show multimodal spectra. 


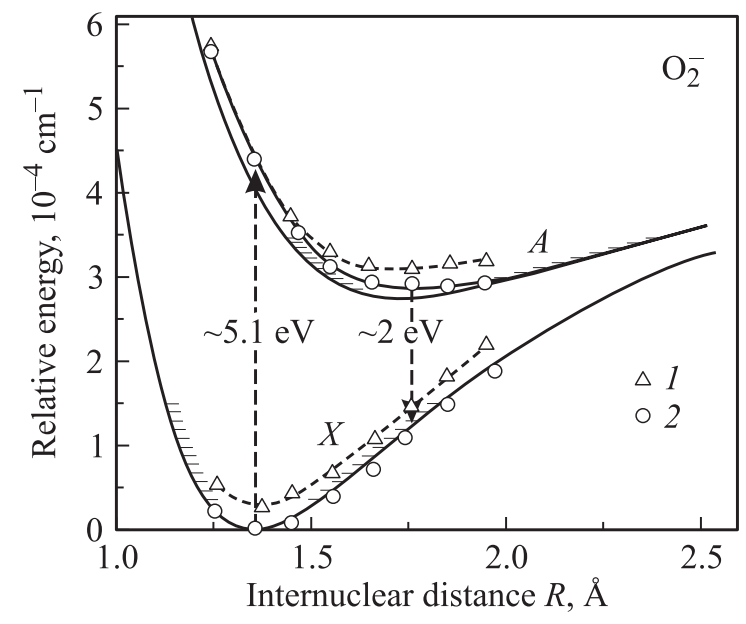

Figure 3. Comparison of MCSCF potential calculations in vacuum (1) and in lattice (2) with experimental Morse curves derived from analysis of absorption, excitation and luminescence spectra of $\mathrm{O}_{2}^{-}$in $\mathrm{NaCl}$ [13]. Respective vibronic levels are shown by bars.

responsible for the red $(\mathrm{R})$ luminescence in $\mathrm{SiO}_{2}$ (see above and [4]). Looking to literature, we found excitation [12] and emission spectra [13] of the negatively charged molecule $\mathrm{O}_{2}^{-}$ on interstitial sites in alkali halide crystals. Especially in [13], the ground electronic state and several low-lying excited states of the superoxide ion $\mathrm{O}_{2}^{-}$have been studied by multiconfiguration self-consistence fields (MCSCF) (see Fig. 3). For comparison, also the ground state of the neutral $\mathrm{O}_{2}$ molecule was considered. Parallel computation were carried out for the species in vacuum and in a simulated $\mathrm{KCl}$ crystal lattice. Computed spectroscopic parameters are in good agreement with experiment for $X$ and $A$ states of $\mathrm{O}_{2}^{-}$in vacuum. In Fig. 3 there is also substantial agreement between the computed energy curves for both the ground $X$ and the excited $A$ states in a point-charge lattice and those measured in alkali halide lattices. Further, the spectroscopic parameters of the electron scattering resonance states in vacuum agree well with those of the analogous lattice-stabilized excited electronic states in the solid. There is a typical absorption from the ground state $X$ to the excited state $A$ at photon energy $h v \approx 5.1 \mathrm{eV}$ corresponding to the red $(\mathrm{R})$ luminescence excitation associated with the non-bridging oxygen hole center (NBOHC) [6]. Moreover, the related luminescent transition $A \rightarrow X$ shows the red (R) luminescence at about $h v=2 \mathrm{eV}$. Looking to vibronic levels within the potential configuration curves we see levels of $\sim 120 \mathrm{meV}$ step widened towards higher potential energies, i.e. towards the red $(\mathrm{R})$ luminescence transition region. These are in good agreement with our $\mathrm{CL}$ spectra of $\mathrm{SiO}_{2}: \mathrm{O}$ and $\mathrm{SiO}_{2}: \mathrm{S}$ layers. Thus we favour the intersitial $\mathrm{O}_{2}^{-}$model for the multimodal CL structure against the concept of a photonic crystal structure [14], the more so as the geometry of the oxygen implanted layers with a thickness of $d=100 \mathrm{~nm}$ and the sulfur implanted layers with $d=500 \mathrm{~nm}$ are fully different (see Fig. 1). Also their implantation profiles differ from each other in depth and width as well as in species kind of implanted ions: $\mathrm{O}^{+}$ and $\mathrm{S}^{+}$. Thus only oxygen and its interstitial molecules remain as candidates for the electronic-vibronic multiple spectra. In case of sulfur implantation the oxygen is likely released from the $\mathrm{SiO}_{2}$ network and, probably, substituted by sulfur atoms, leading to free oxygen and finally to $\mathrm{O}_{2}^{-}$ molecules in interstitial sites.

\section{Conclusion}

Thermally oxidized $\mathrm{SiO}_{2}$ layers of 100 and $500 \mathrm{~nm}$ thickness have been implanted by different ions with a dose $3 \cdot 10^{16}$ and $5 \cdot 10^{16} \mathrm{~cm}^{-2}$, respectively, leading to the atomic dopant fraction of about 4 at $\%$ at the half depth of the $\mathrm{SiO}_{2}$ layers. As a surprizing pecularity, the cathodoluminescence spectra of oxygen and sulfur implanted $\mathrm{SiO}_{2}$ layers show besides characteristic bands a sharp and intensive multimodal structure beginning in the green region at $500 \mathrm{~nm}$ over the yellow-red region and extending to the near IR measured up to $820 \mathrm{~nm}$. The energy step differences of the sublevels amount in average $120 \mathrm{meV}$ and indicate vibration associated elecronic states, probably of $\mathrm{O}_{2}^{-}$interstitial molecules, as we could demonstrate by a respective configuration coordinate model.

\section{References}

[1] I. Fanderlik. Silica Glass and it's Application (Elsevier, 1991).

[2] G. Pacchioni, L. Skuja, D.L. Griscom. Defects in $\mathrm{SiO}_{2}$ and Related Dielectics: Science and Technology. NATO Science Series (Kluwer Academic, Dordrecht, 2000).

[3] M.A. Stevens Kalceff. Phys. Rev. B, 57, 5674 (1998).

[4] H.-J. Fitting, T. Barfels, A.N. Trukhin, B. Schmidt, A. Gulans, A. von Czarnowski. J. Non-Cryst. Sol., 303, 218 (2002).

[5] D.L. Griscom. Rev Sol. St. Sci., 4, 565 (1990).

[6] L. Skuja. J. Non-Cryst. Sol., 167, 229 (1994).

[7] A.N. Trukhin, M. Goldberg, J. Jansons, H.-J. Fitting, I.A. Tale. J. Non-Cryst. Sol., 223, 114 (1998).

[8] H.-J. Fitting, T. Ziems, A. von Czarnowski, B. Schmidt. Radiation Measurements, 38, 649 (2004).

[9] R.H. Magruder, R.A. Weeks, R.A. Weller, R.A. Zuhr. J. Non-Cryst. Sol., 304, 224 (2002).

[10] Roushdey Salh, B. Schmidt, H.-J. Fitting. Phys. Status Solidi A, 202, R53 (2005).

[11] H.-J. Fitting, Roushdey Salh, T. Barfels, B. Schmidt. Phys. Status Solidi A, 202, R142 (2005).

[12] J. Rolfe. J. Chem. Phys., 70, 2463 (1979).

[13] C.S. Ewig, J. Tellinghuisen. J. Chem. Phys., 95, 1097 (1991).

[14] R.C. Bailey, M. Parpia, J.T. Hupp. Materials Today (April 2005) p. 46.

Редактор Л.В. Шаронова 